\title{
Short-Term Outcome of "Double Crown" Tackers Mesh Fixation in Laparoscopic Ventral Hernia Repair
}

\author{
Tamer A. El-Bakary¹, S. Abdelaziem², A. Abdel Hafiz' ${ }^{1}$, Mohamed S. Hashish ${ }^{2 *}$ \\ ${ }^{1}$ Department of General Surgery, Hamad Medical Corporation (HMC), Doha, Qatar \\ ${ }^{2}$ Department of General Surgery, Tanta University Hospital, Tanta, Egypt \\ Email: ${ }^{*}$ dr_mohamed_hashish@yahoo.com
}

Received 3 January 2015; accepted 26 February 2015; published 28 February 2015

Copyright (C) 2015 by authors and Scientific Research Publishing Inc.

This work is licensed under the Creative Commons Attribution International License (CC BY). http://creativecommons.org/licenses/by/4.0/

(c) (7) Open Access

\begin{abstract}
Background: Many ventral hernia repair methods have been described among surgeons. The traditional primary repair entails a laparotomy with suture approximation of strong fascial tissue on each side of the defect. However, recurrence rates after this procedure range from $12 \%$ to $24 \%$ during long-term follow-up. Laparoscopic ventral hernia repair (LVHR) is a well recognized minimally invasive surgical technique for repair of different types of abdominal wall ventral hernias. However, the best method of mesh fixation during LVHR is still a subject of debate. Patients \& Methods: In the present study, 50 patients were presented with ventral hernia between June 2012 and October 2013. Demographics of the patients were recorded. All patients were submitted to LVHR with mesh fixation by "Double Crown" of tackers. The first crown was placed on the mesh periphery with $1 \mathrm{~cm}$ between each 2 successive tackers and the second crown around the edges of the defect. Operative complications, VAS scale, post-operative complications, and length of hospital stay were reported. Results: The mean age was 40.08 years. Female to male ratio was 3:2. The mean BMI was 32.3. The diameter of the hernial defect was $<5 \mathrm{~cm}$ in $64 \%$, while, the defects larger than $15 \mathrm{~cm}$ were excluded. LVHR was successfully completed in all the patients with no conversion. Only 1 patient had intra-operative bleeding from omental vessels that was successfully controlled. The mean operative time was 79 minutes. Post-operatively, the mean VAS was 3.96, 2.12, and 0.24 at 24 hours, 2 weeks, and 4 weeks, respectively. Two patients developed post-operative ileus that was treated conservatively and 1 patient developed persistent seroma that was treated by repeated aspiration. The mean length of hospital stay was 3.08 days. Conclusion: "Double Crown" tackers mesh fixation in LVHR seems to be a safe and effective surgical technique with favorable outcome. However, further randomized studies are needed on larger numbers of patients to validate these results.
\end{abstract}

\footnotetext{
"Corresponding author.
}

How to cite this paper: El-Bakary, T.A., Abdelaziem, S., Hafiz, A.A. and Hashish, M.S. (2015) Short-Term Outcome of "Double Crown" Tackers Mesh Fixation in Laparoscopic Ventral Hernia Repair. Surgical Science, 6, 100-108. 


\section{Keywords}

\section{Laparascopic, Verntral Hernia, Double Crown Fixation}

\section{Introduction}

Ventral hernia is a common surgical disorder. It may be either primary (including umbilical, para-umbilical, epigastric, and Spigelian hernia) or secondary which is commonly known as incisional hernia [1] [2]. The traditional repair consists of open closure of the facial defect with implantation of a mesh which requires extensive dissection and it results in recurrence rate of $12 \%-24 \%$ [3].

Laparoscopic ventral hernia repair (LVHR) with intra-peritoneal mesh placement to cover the defect was first described by LeBlanc and Booth in 1993 [4]. In a meta-analysis on 8 randomized clinical trials, LVHR was found to be as effective, if not superior to the open repair [5]. LVHR showed shorter hospital stay, less wound infection, with the same or even lower recurrence rates. So, LVHR is gaining more acceptance worldwide. However, controversy still exists concerning management of large hernial sacs, post-operative seroma, type of the mesh and the method of mesh fixation [6].

The introduction of new generation of light weight bilaminar meshes has encouraged more surgeons to use LVHR technique as it is believed that this veneer facing the bowel is safer and less likely to create erosion or fistulization [7]. A point of hot debate among surgeons in LVHR is the method of mesh fixation to the abdominal wall, many surgeons believe that, suture fixation of the mesh by "The Transfacial Sutures" is mandatory [3] [8]. They claimed that, fixation with only tackers was relatively weaker as the tackers did not fix the mesh to muscles and fascia as they penetrated through few millimeters of the abdominal wall and this may lead to partial or complete mesh displacement leading to recurrence [9].

On the other hand, other surgeons prefer to fix the mesh with only tackers without any transracial sutures [10]-[12]. These surgeons found that tackers-only fixation significantly reduced the operative time, avoided parietal vascular injuries, decreased post-operative pain and maintained a similar recurrence rate.

Morales-Conde et al. [13] advocated the use of "Double Crown" tacker mesh fixation and they found this technique to be more superior than mesh fixation by sutures and tackers. Moreover, LeBlanc [14], in 2007, advised a larger mesh overlap ( 5 versus $3 \mathrm{~cm}$ ) if sutures were not used. In this study, we will discuss the short-term outcomes of LVHR with mesh fixation by double crown of absorbable tackers without the use of transfacial sutures.

\section{Patients and Methods}

Between June 2012and October 2013, fifty patients presented with ventral hernia were submitted to laparoscopic repair (LVHR) in Hamad Medical Corporation (HMC), Doha, Qatar. The study protocol was fully approved by legal ethical approval number: HMC 41020027. Demographics of the patients were recorded. Exclusion criteria included patients with hernial defect larger than $15 \mathrm{~cm}$, and patients with hernias close to bony structures as the mesh in these hernias cannot be fixed by tackers only.

The surgical technique was discussed with each patient and informed consent was taken. All the patients received prophylactic antibiotics in the form of $1 \mathrm{gm}$ Cefotaxime Sodium with the induction of anesthesia and it was continued 12 hourly post-operatively for 24 hours. Surgery was performed with the patient placed in supine position. The surgeon and the assistant are on the side of the patient which is opposite to the ventral hernia. If the hernia is in the midline, the surgeons stood on the left side. The trocars were inserted as lateral as possible from the hernial defect. Open technique was used to introduce $12 \mathrm{~mm}$ trocar at the level of the umbilicus to create artificial pneumoperitoneum with insertion of 30 degrees scope. Then, two $5 \mathrm{~mm}$ trocars were inserted under vision cephalic and caudal to the first trocar. Another $5 \mathrm{~mm}$ port was inserted in the opposite side of the abdomen in some cases where we found difficulty in dissection or fixation of the mesh.

Adhesiolysis was performed by taking down the omentum and bowel adhesions using the scissors trying to avoid the use of diathermy as much as possible to minimize the risk of thermal injury. Adhesiolysis was continued till the edges of the defect were completely and clearly exposed to a distance of at least $5 \mathrm{~cm}$. Any adjacent small defects that might be non-obvious pre-operatively must be also exposed to be covered by the mesh 
(Figure 1). Then, the pneumoperitoneum was reduced to $8 \mathrm{mmHg}$. Sterile ruler was introduced to measure the maximum diameter of the defect to fashion the proper mesh size that provides $5 \mathrm{~cm}$ overlap of the edges of the defect in all directions (Figure 2).

We used Parietex Optimized Composite (PCO) mesh (Covidien, USA) which is polyester knit mesh from one side and the other side is covered by absorbable collagen barrier to prevent visceral adhesions. The mesh has 2 prolene stitches that help in mesh orientation and fixation. The mesh was rolled up and introduced through the $12 \mathrm{~mm}$ trocar. Then, it was oriented to make the non-adherent face toward the bowel and to overlap the defect edges by $5 \mathrm{~cm}$ in different directions. Two small incisions (each is about $1 \mathrm{~mm}$ ) were made in the abdominal wall at 6 and 12 o'clock. The endo-close was passed through these incisions to take the prolene sutures fixed to the mesh and pull them out through the abdominal wall. These 2 sutures help to keep the mesh hanged up on the abdominal wall and centered on the defect while fixing it. The mesh was fixed to the abdominal wall by double crown of Securestrap Tackers (Ethicon, USA) which is absorbable tackers measuring $6.7 \mathrm{~mm}$ in length. It become completely absorbed in 12 months after critical tissue integration has occurred. The first crown was applied on the mesh periphery with $1 \mathrm{~cm}$ between each 2 successive tackers (Figure 3).

The second crown was applied around the edge of the defect (Figure 4). Counter-pressure on the anterior abdominal wall is needed during application of the tackers to help them to penetrate through the pre-peritoneal muscular fascia.

At the end, the 2 prolene stitches hanging the mesh were cut. The ports were removed and the sheath at the site of $12-\mathrm{mm}$ port was closed under vision. Pressure dressing was applied at the site of the hernia to reduce the incidence of seroma formation.

Post-operatively, the patients were kept on Pethidine $50 \mathrm{mg}$ intra-muscularly every 8 hours and started oral intake once the bowel sounds became audible. The patients were discharged once they tolerated full oral intake,

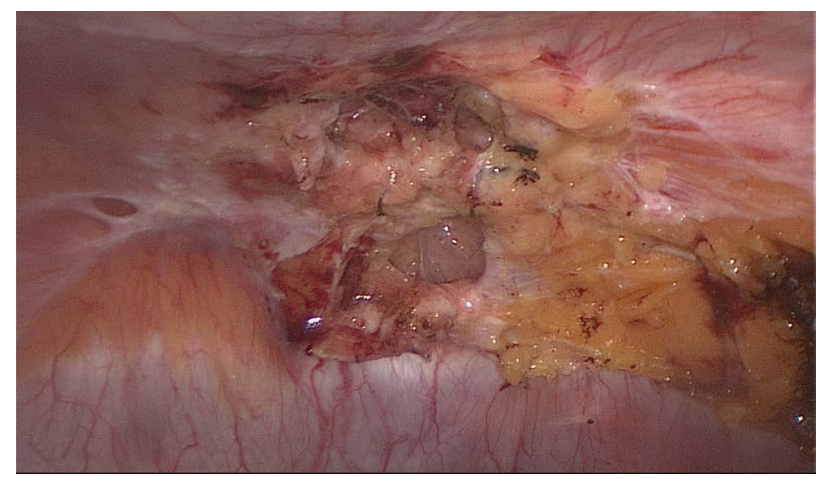

Figure 1. Exposure of the edges of the defect.

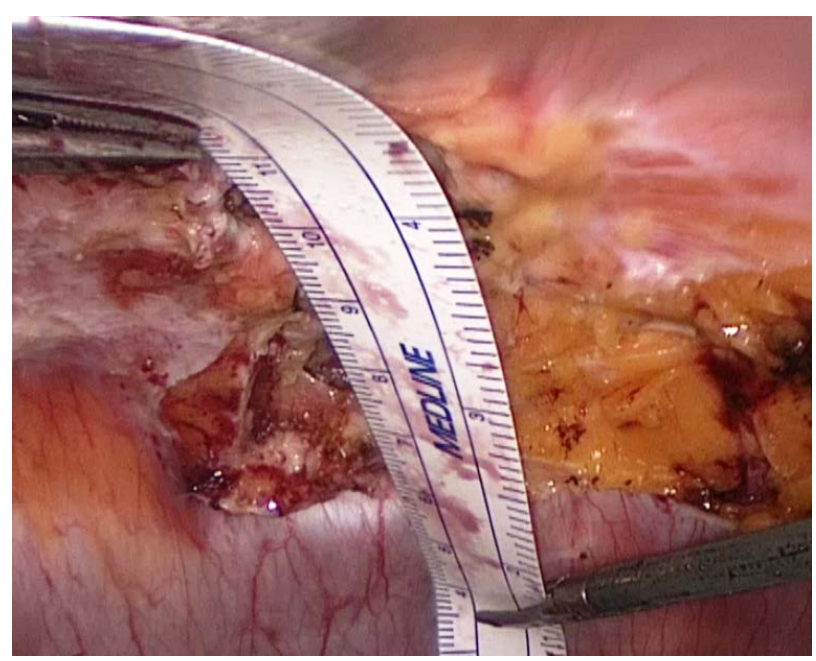

Figure 2. Measuring the diameter of the hernia defect. 


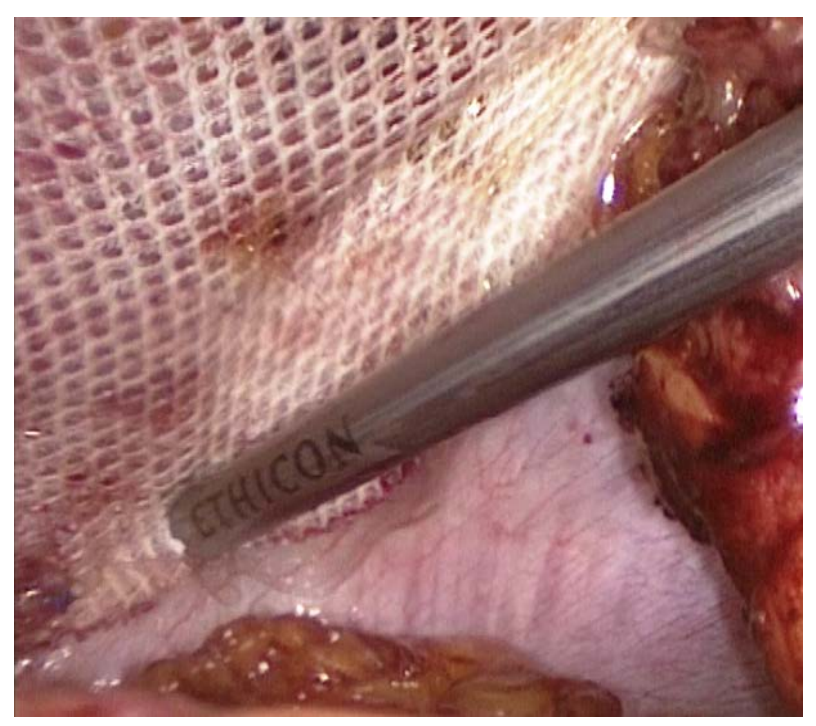

Figure 3. The first crown of tackers.

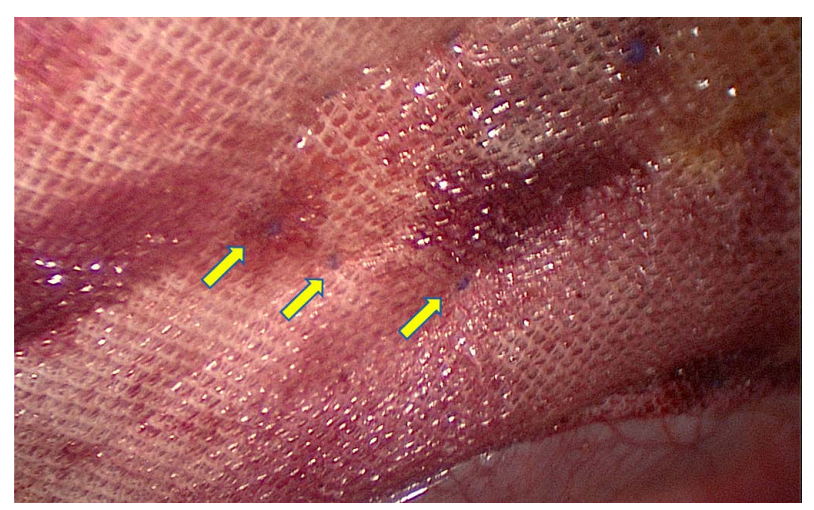

Figure 4. The second crown of tackers.

no fever, no or mild pain that can be controlled by oral analgesics in the form of Ibuprofen 400 mg twice daily. All the patients were reviewed in the out-patient clinic 2 weeks, 4 weeks, 3 months, 6 months and 1 year.

\section{Results}

\subsection{Demographic}

Fifty patients with ventral hernias were enrolled in the study and were submitted to LVHR. The age of the patients ranged between 25 \& 59 years with the mean of 40.08 years (Table 1$)$. Thirty patients (60\%) were females and 20 were males (40\%). The body mass index (BMI) ranged between 24.1 and 38.4 with a mean of 32.3 $\mathrm{Kg} / \mathrm{m}^{2}$.

\subsection{Hernia Character}

Twenty eight patients (56\%) had para-umbilical hernia (Table 2), 12 patients (24\%) had epigastric hernia, and 10 patients (20\%) had incisional hernia. The diameter of the hernial defect was less than $5 \mathrm{~cm}$ in 32 patients (64\%), 5 - $10 \mathrm{~cm}$ in 14 patients (28\%), and $10-15 \mathrm{~cm}$ in 4 patients (8\%) and in these 4 patients, a fourth $5 \mathrm{~mm}$ trocar was introduced in the opposite side to facilitate dissection and fixation (Table 2).

\subsection{Operative Data}

The operative time ranged between 68 and 133 minutes with a mean of 79 minutes. 
Intra-operative complications included hemorrhage from omental vessels in 1 patient (2\%) that was controlled by cautery and clips, serosal tears of the small bowel in 3 patients (6\%) during adhesiolysis and it didn't need any repair. No full thickness bowel injury was reported. All the cases were successfully completed laparoscopically with no need to conversion to open surgery.

\subsection{Post Operative Outcome Results}

Length of hospital stay ranged between 2 and 6 days with a mean of 3.08 days.

Post-operatively, VAS score was recorded for all the patients. The mean VAS score 24 hour post-operatively was 3.96. It was 2.12 and 0.24 at 2 weeks and 4 weeks respectively. At 3 months, only 6 patients (12\%) had VAS score equal or more than 1.

Post-operative ileus was recorded in 2 patients (4\%) who couldn't tolerate oral intake with vomiting and abdominal distention. They were treated by naso-gastric tube and IV fluids. They were discharged $5 \& 6$ days respectively. During the follow-up period, no wound infection was recorded. Mild asymptomatic seroma was observed in 8 patients $(16 \%)$ and it resolved spontaneously without aspiration. Persistant seroma more than 8 weeks was recorded in only 1 patient (2\%) and it was treated by repeated aspiration. No hernia recurrence recorded in any patient during the follow-up period that ranged between 12 and 22 months (Table 3).

\begin{tabular}{lc}
\hline Table 1. Patients' demographics. \\
\hline Patients' demographics & Value \\
\hline \multicolumn{1}{|c|}{ Mean age } & 40.08 years \\
Female/male & $3 / 2$ \\
Mean BMI & 32.3 \\
\hline Table 2. Hernia characteristics. & \\
\hline Hernia characteristic & No. of the patients (\%) \\
\hline Type: & \\
\hline Para-umbilical & $28(56)$ \\
Epigastric & $12(24)$ \\
Incisional & $10(20)$ \\
Defect size: & \\
Less than 5 cm & $32(64)$ \\
5 - 10 cm & $14(28)$ \\
10 - $15 \mathrm{~cm}$ & $4(8)$ \\
\hline
\end{tabular}

Table 3. Outcome result.

\begin{tabular}{cc}
\hline Outcome result & (Mean \pm SD) \\
\hline Operative time min & $79 \pm 36.1$ \\
Hospital stay day & $3.08 \pm 1.2$ \\
\hline Postoperative morbidity & Patients (n\%) \\
\hline Ileus & $2(4 \%)$ \\
Wound infection & $0(0 \%)$ \\
Prolonged seroma (>8 weeks) & $1(2 \%)$ \\
Prolonged pain (>3 months) & $6(0 \%)$ \\
Hernia recurrence & $0(0 \%)$ \\
\hline
\end{tabular}




\section{Discussion}

Laparoscopic ventral hernia repair is nowadays a widely accepted surgical technique after the publication of many systemic reviews over the last few years [5] [15]-[17]. Accumulating evidence suggests that LVHR is at least as safe as the open repair not only with the same or even less risk of peri-operative complications and recurrence but also with less wound infection rates and shorter hospital stay [5]. The discussion about the best method of mesh fixation during LVHR is still ongoing. Many reviews were done to compare transfacial sutures and "Double Crown" of tackers. None of these could find superiority of one technique over the other [18] [19]. Transfacial sutures significantly increase the operative time [20], produce acute and chronic post-operative abdominal wall pain [21], and not associated with lower recurrence rates [10].

The mean age of the patients in our study was 40.08 years which was younger in compared with other studies as Sasse et al. [22] with the mean age was 56.9 years, and Muysoms et al. [18] with the mean age was 59.8 years.

In our study the mean BMI was 32.3 which was matched with other studies as In a study by Sasse et al. [22] and Muysoms et al. [18] with the mean BMI was 33.1 and 29.3, respectively.

As regard the width of the hernia, in the present study, 32 hernias (64\%) are less than $5 \mathrm{~cm}, 14$ hernias (28\%) are $5-10 \mathrm{~cm}$, and 4 hernias (8\%) are $10-15 \mathrm{~cm}$ in diameter. Chevrel and Rath [23] in their study stated that the width of the hernia is the most important factor that determines the success of the hernia repair. They classified the hernia into 4 groups: small (W1) with hernia less than $5 \mathrm{~cm}$, medium (W2) with hernia 5 - $10 \mathrm{~cm}$, large (W3) with hernia 10 - $15 \mathrm{~cm}$, and giant (W4) with hernia larger than $15 \mathrm{~cm}$ in diameter. They concluded in their study that W3 \& W4 includes hernias which are most difficult to repair with the highest potential risk of recurrence. The width of hernial orifice more than $10 \mathrm{~cm}$ has been reported to be a significant risk factor of recurrence regardless the technique, open or laparoscopic [24]. These higher recurrence rates may be attributed to technical difficulties in lateral fixation and insufficient lateral overlap of the mesh [25]. So, we excluded W4 hernias from the study.

PCO mesh (Covidien, USA) was used in all of our patients that was fixed by Securestarp tackers (Ethicon, USA) which are absorbable with no exposed sharp edges. The classic polypropylene meshes can't be used in LVHR because many cases of intestinal erosions and fistulization were reported with these meshes in different studies [26] [27]. Many new mesh materials emerged in the last few years to be used in LVHR. All of these meshes have smooth side facing the viscera to act as an adhesion barrier. However, long-term future studied are needed to determine if these new bilaminar meshes effectively prevent adhesions between viscera and mesh or not [22].

The old metal tackers should not be used anymore as they can induce ileus and bowel injury due to direct contact of the bowel with these exposed metallic tackers [22]. During application of tackers, we decided to have 1 - $2 \mathrm{~cm}$ between each 2 successive tackers as advised by many authors. This distance was found to reduce the incidence of recurrence [28] and to prevent herniation of the bowel in the gaps between the tackers in the outer ring of the double crown [29]. To reduce the post-operative pain, Sharma et al. [30] tried to reduce the number of tackers by applying them at 3-cm intervals with no recurrence.

The need of mesh fixation by stitches is still a matter of debate. Heniford et al. [3] stated that suture fixation is mandatory in LVHR to reduce recurrence. LeBlanc et al. [8] considered transfacial sutures are critical to fix the mesh. On the other hand, other studies [10] [11] [31] concluded that tackers-only mesh fixation significantly reduces operative time, overall complications rate with a similar recurrence rate. Muysoms et al. [18] in their study found a recurrence rate at 24 months of 11.1\% after stitches and tackers and of 3.7\% after "Double Crown" tackers fixation. They concluded that the most important factor in determining recurrence is not the method of fixation but the "effective interface" of the parietal side of the mesh with the abdominal wall. They claimed that the inner crown of tackers increases this "effective interface" between the two crowns. With single crown, this interface and the subsequent proper mesh ingrowth will decrease because of abdominal wall movement and seroma formation around the mesh. So, the use of single crown of tackers even with stitches is not valid anymore and a second crown of tackers around the edges of the defect must be added [18]. New studies are going on to increase the "effective interface" to nearly the complete mesh surface by new techniques of fixation like glue and self-fixating mesh [32].

The crucial point in "Double Crown" mesh fixation without transfacial stitches is that a larger overlap of the mesh beyond the edges of the defect is needed. Three cm overlap was generally accepted recommendation at the 
start of LVHR. However, current recommendation requires a minimum overlap of $5 \mathrm{~cm}$ specially in patients with hernial defects more than $5 \mathrm{~cm}$ in diameter [3] [8] [11] [14].

In our study, the mean operative time was 79 minutes. Intra-operatively, 1 patient had bleeding from omental vessels that was successfully controlled and 3 patients had serosal bowel tears. No conversion to open technique was needed. The mean length of hospital stay was 3.08 days. These results are comparable with results of other studies. Baccari et al. [25] reported operative time of 72.3 minutes with a full thickness bowel injury in $2.2 \%$ of cases and a conversion rate of $1.4 \%$ and a mean length of hospital stay of 3 days. Muysoms et al. [18] had operative time of 74 minutes with serosal bowel injury in 1 out of 32 patients and conversion to open surgery in 1 patient. They had a mean length of hospital stay of 3.9 days. Colon et al. [33] reported operative time of 106 minutes with no operative complications or conversion.

The post-operative pain is of great concern in LVHR as it increases consumption of pain killers, increases the incidence of post-operative ileus and subsequently prolongs the length of hospital stay [34]. Mesh fixation with only tackers was found to reduce post-operative pain and length of hospital stay [35] if compared to transfacial stitches. The mean VAS in our study was 3.96, 2.12, and 0.24 at 24 hours, 2 weeks, and 4 weeks post-operatively respectively. Only 6 patients had VAS more than 1 at 3 months post-operatively. These results are more or less similar to results of other studies. Muysoms et al. [18] reported a VAS score of 3.1 at rest at 24 hours and 3.9 at 4 weeks post-operatively. At 3 months, they reported a VAS of 0.05 at rest. Bansal et al. [34] reported a mean VAS of 1.3 at 6 weeks post-operatively in cases of tackers only mesh fixation, while Beldi et al. [36] had a mean VAS of 2.5 at 6 weeks after surgery.

Post-operative complications in the present study were post-operative ileus in 2 patients and persistent seroma in 1 patient. No wound infection was reported. No recurrence was encountered during a mean follow-up of 20.56 months. These results compare favorably with results of other studies. Colon et al. [33] reported in their study 1 case of post-operative ileus (2.5\%) and $4 \%$ incidence of wound infection after 40 LVHR with no recurrence. Baccari et al. [25] reported 1.4\% incidence of prolonged ileus, $0.3 \%$ incidence of prolonged seroma ( $>8$ weeks), and recurrence rate of $1.1 \%$ after 12 months follow-up in a series of 280 LVHR in patients with hernial defect less than $15 \mathrm{~cm}$. Sasse et al. [22] published their study on 225 LVHR with 42 months follow-up. They reported $0.44 \%$ incidence of large seroma, $6.22 \%$ incidence of ileus, and a recurrence rate of $0.89 \%$.

It is not surprising that the incidence of surgical site infection seems to be much lesser after LVHR if compared to the open approach because LVHR, unlike the open approach, involved almost no dissection of the subcutaneous tissue, and the incisions are smaller, making bacterial migration to the subcutaneous space less likely [37].

Seroma formation is one of the commonest complications after LVHR [38]. Its average incidence is about 5.4\% [39]. Morales-Conde [40] in his review considered most of these seroms as just an incident as they did not cause any problems to the patient and he classified this seroma into 5 types: type 0 , no clinical seroma; type I, clinical seroma lasting less than 1 month; type II, clinical seroma lasting 1 and 6 months; type III, symptomatic seroma that may need medical treatment including seromas lasting more than 6 months, esthetic complaints, discomfort, pain, or superficial infection; type IV, major seroma related complications (need to puncture, seroma drained spontaneously, applicable to open approach, deep infection, recurrence, and mesh rejection). So, according to this classification, only types III and IV need intervention. However, according to Ujiki et al. [15], seroma is considered as a complication of LVHR if it persists more than 8 weeks, increases in size, or it becomes symptomatic.

According to our knowledge, no previous series published short-term follow-up in "Double Crown" Tackers Mesh Fixation in Laparoscopic Ventral Hernia Repair, our period of follow-up (12 - 24 months with mean of 12.4 month) was almost short in comparison with other series as Sasse et al. [22] published their study on 225 LVHR with 42 months follow-up and Morales-Conde et al. [13] in their experience after 140 cases with a mean follow-up of 40 months.

In conclusion, results of this study suggest that LVHR is a safe and feasible technique. It is associated with low rates of complications and hernia recurrence. It provides the patient a good quality of life. However, further randomized studies with longer follow-up period are needed to assess the validity of these results.

\section{References}

[1] Lomanto, S., Iyer, G., Shabbir, A. and Cheah, W.K. (2006) Laparoscopic versus Open Ventral Hernia Mesh Repair: A Prospective Study. Surgical Endoscopy, 20, 1030-1035. http://dx.doi.org/10.1007/s00464-005-0554-2 
[2] Hoer, J., Lawong, G. and Klinge, U. (2002) Factors Influencing the Development of Incisional Hernia: A Retrospective Study of 2983 Laparotomy Patients over a Period of 10 Years. Chirurgie, 73, 474-480.

[3] Heniford, B., Park, T., Ramshaw, B.J. and Voller, G. (2003) Laparoscopic Repair of Ventral Hernia: Nine Years Experience with 850 Consecutive Hernia. Annals of Surgery, 238, 391-399.

[4] LeBlanc, K.A. and Booth, W.V. (1993) Laparoscopic Repair of Incisional Hernias Using Expanded Polytetrafluoroethylene: Preliminary Findings. Surgical Laparoscopy Endoscopy, 3, 39-41.

[5] Forbes, S.S., Eskicioglu, C., Mcleod, R.S. and Okrainec, A. (2009) Meta-Analysis of Randomized Controlled Trials Comparing Open and Laparoscopic Ventral and Incisional Hernia Repair with Mesh. British Journal of Surgery, 96, 851-858. http://dx.doi.org/10.1002/bjs.6668

[6] Sajid, M.S., Parampalli, U. and McFall, M.R. (2013) A Meta-Analysis Comparing Tacker Mesh Fixation with Suture Mesh Fixation in Laparoscopic Incisional and Ventral Hernia Repair. Hernia, 17, 159-166. http://dx.doi.org/10.1007/s10029-012-1017-z

[7] Cobb, W.S., Kercher, K.W. and Heniford, B.T. (2005) The Argument of Light Weight Polypropylene Mesh in Hernia Repair. Surgical Innovation, 12, 63-71. http://dx.doi.org/10.1177/155335060501200109

[8] LeBlanc, K.A., Whitaker, J.M., Bellanger, D.E. and Rhynes, V.K. (2003) Laparoscopic Incisional and Ventral Hernioplasty: Lessons Learned from 200 Patients. Hernia, 7, 118-122. http://dx.doi.org/10.1007/s10029-003-0117-1

[9] van’t Riet, M., de Vos van Steenwijk, P.J., Kleinrensink, G.J., et al. (2002) Tensile Strength of Mesh Fixation Methods in Laparoscopic Incisional Hernia Repair. Surgical Endoscopy, 16, 1713-1716. http://dx.doi.org/10.1007/s00464-001-9202-7

[10] Rudmik, L.R., Scheiman, C., Dixon, E., et al. (2006) Laparoscopic Incisional Hernia Repair: A Review of the Literature. Hernia, 10, 110-119. http://dx.doi.org/10.1007/s10029-006-0066-6

[11] Carbajo, M.A., Martin Del Olmo, J.C., Blanco, J.I., Toledano, M., Cuesta, C., Ferreras, C. and Vaquero, C. (2003) Laparoscopic Approach to Incisional Hernia. Lessons Learned from 270 Patients over 8 Years. Surgical Endoscopy and Other Interventional Techniques, 17, 118-122. http://dx.doi.org/10.1007/s00464-002-9079-0

[12] Baccari, P., Nifosi, J., Ghirardelli, L. and Staudacher, C. (2009) Laparoscopic Incisional and Ventral Hernia Repair without Sutures: A Single-Center Experience with 200 Cases. Journal of Laparoendoscopic \& Advanced Surgical Techniques, 19, 175-179. http://dx.doi.org/10.1089/lap.2008.0244

[13] Morales-Conde, S., Cadet, H., Cano, A., Bustos, M., Martín, J. and Morales-Mendez, S. (2005) Laparoscopic Ventral Hernia Repair without Sutures_-Double Crown Technique: Our Experience after 140 Cases with a Mean Follow-Up of 40 Months. International Surgery, 90, S56-S62.

[14] LeBlanc, K.A. (2007) Laparoscopic Incisional Hernia Repair: Are Transfacial Sutures Necessary? A Review of the Literature. Surgical Endoscopy, 21, 508-513. http://dx.doi.org/10.1007/s00464-006-9032-8

[15] Ujiki, M.B., Weinberger, J., Varghese, T.K., Murayama, K.M. and Joehl, R.J. (2004) One Hundred Consecutive Laparoscopic Ventral Hernia Repairs. American Journal of Surgery, 188, 593-597. http://dx.doi.org/10.1016/j.amjsurg.2004.07.010

[16] Kapischke, M., Schulz, T., Schipper, T., Tensfeldt, J. and Caliebe, A. (2008) Open versus Laparoscopic Incisional Hernia Repair: Something Different from a Meta-Analysis. Surgical Endoscopy, 22, 2251-2260. http://dx.doi.org/10.1007/s00464-008-9773-7

[17] Pham, C.T., Perera, C.L., Watkin, D.S. and Maddern, G.J. (2009) Laparoscopic Ventral Hernia Repair: A Systematic Review. Surgical Endoscopy, 23, 4-15. http://dx.doi.org/10.1007/s00464-008-0182-8

[18] Muysoms, F., Vander Mijnsbrugge, G., Pletinckx, P., Boldo, E., Jacobs, I., Michiels, M. and Ceulemans, R. (2013) Randomized Clinical Trial of Mesh Fixation with "Double Crown” versus "Sutures and Tackers" in Laparoscopic Ventral Hernia Repair. Hernia, 17, 603-612. http://dx.doi.org/10.1007/s10029-013-1084-9

[19] Brill, J.B. and Turner, P.L. (2011) Long-Term Outcomes with Transracial Sutures versus Tacks in Laparoscopic Ventral Hernia Repair: A Review. American Surgeon, 77, 458-465.

[20] Wassenaar, E.B., Raymakers, J.T. and Rakic, S. (2008) Impact of Mesh Fixation Technique on Operation Time in Laparoscopic Repair of Ventral Hernias. Hernia, 12, 23-25. http://dx.doi.org/10.1007/s10029-007-0269-5

[21] Carbonell, A.M., Harold, K.L., Mahmutovic, A.J., Hassan, R., Matthews, B.D., Kercher, K.W., et al. (2003) Local Injection for the Treatment of Suture Site Pain after Laparoscopic Ventral Hernia Repair. American Surgeon, 69, 688691.

[22] Sasse, K.C., Lim, D.C.L. and Brandt, J. (2012) Long-Term Durability and Comfort of Laparoscopic Ventral Hernia Repair. Journal of the Society of Laparoendoscopic Surgeons, 16, 380-386.

[23] Chevrel, J.P. and Rath, A.M. (2000) Classification of Incisional Hernias of the Abdominal Wall. Hernia, 4, 7-11. http://dx.doi.org/10.1007/BF01230581 
[24] Kurmann, A., Visth, E., Candinas, D. and Beldi, G. (2011) Long-Term Follow-Up of Open and Laparoscopic Repair of Large Incisional Hernias. World Journal of Surgery, 35, 297-301. http://dx.doi.org/10.1007/s00268-010-0874-9

[25] Baccari, P., Nifosi, J., Ghirardelli, L. and Staudacher, C. (2013) Short- and Mid-Term Outcome after Laparoscopic Repair of Large Incisional Hernia. Hernia, 17, 567-572. http://dx.doi.org/10.1007/s10029-012-1026-y

[26] Leber, G.E., Garb, J.L., Alexander, A.I. and Reed, W.D. (1998) Long Term Complications Associated with Prosthetic Repair of Incisional Hernias. JAMA Surgery, 133, 378-382. http://dx.doi.org/10.1001/archsurg.133.4.378

[27] Basoglu, M., Yildirgan, M.I., Yilmaz, I., Balik, A., Celebi, F., Atamanalp, S.S., Polat, K.Y. and Oren, D. (2004) Late Complications of Incisional Hernias Following Prosthetic Mesh Repair. Acta Chirurgica Belgica, 104, 425-428.

[28] Wassenaar, E., Schoenmaeckers, E., Raymakers, J., van der Palen, J. and Rakic, S. (2010) Mesh Fixation Method and Pain and Quality of Life after Laparoscopic Ventral or Incisional Hernia Repair: A Randomized Trial of Three Fixation Techniques. Surgical Endoscopy, 24, 1296-1302. http://dx.doi.org/10.1007/s00464-009-0763-1

[29] Schoenmaeckers, E., de Haas, R.J., Stirler, V., Raymakers, J.T.F.J. and Rakic, S. (2012) Impact of the Number of Tacks on Post-Operative Pain in Laparoscopic Repair of Ventral Hernias: Do More Tacks Cause More Pain? Surgical Endoscopy, 26, 357-360. http://dx.doi.org/10.1007/s00464-011-1876-x

[30] Sharma, A., Mehrota, M., Khullar, R., Soni, V., Baijal, M. and Chowbey, P.K. (2011) Laparoscopic Ventral/Incisional Hernia Repair: A Single Centre Experience of 1242 Patients over a Period of 13 Years. Hernia, 15, 131-139. http://dx.doi.org/10.1007/s10029-010-0747-z

[31] Greenstein, A.J., Nguyen, S.Q., Buch, K.E., Chin, E.H., Weber, K.J. and Divino, C.M. (2008) Recurrence after Laparoscopic Ventral Hernia Repair: A Prospective Pilot Study of Suture versus Tack Fixation. American Surgeon, 74, 227231.

[32] Eriksen, J.R., Bisgaard, T., Assaadzadeh, S., Nannestad Jorgensen, L. and Rosenberg, J. (2011) Randomized Clinical Trial of Fibrin Sealant versus Titanium Tacks for Mesh Fixation in Laparoscopic Umbilical Hernia Repair. British Journal of Surgery, 98, 1537-1545. http://dx.doi.org/10.1002/bjs.7646

[33] Colon, M.J., Kitamura, R., Telem, D.A., Nguyen, S. and Divino, C.M. (2013) Laparoscopic Umbilical Hernia Repair Is the Preferred Approach in Obese Patients. American Journal of Surgery, 205, 231-236. http://dx.doi.org/10.1016/j.amjsurg.2012.02.022

[34] Bansal, V.K., Misra, M.C., Kumar, S., Keerthi Rao, Y., Singhal, P., Goswami, A., et al. (2011) A Prospective Randomized Study Comparing Suture Mesh Fixation versus Tacker Mesh Fixation for Laparoscopic Repair of Incisional and Ventral Hernias. Surgical Endoscopy, 25, 1431-1438. http://dx.doi.org/10.1007/s00464-010-1410-6

[35] Bellows, Ch. and Berger, D. (2006) Infiltration of Suture Sites with Local Anesthesia for Management of Pain Following Laparoscopic Ventral Hernia Repairs: A Prospective Randomized Trial. Journal of the Society of Laparoendoscopic Surgeons, 10, 345-350.

[36] Beldi, G., Wagner, M., Bruegger, L.E., Kurmann, A. and Candinas, D. (2011) Mesh Shrinkage and Pain in Laparoscopic Ventral Hernia Repair: A Randomized Clinical Trial Comparing Suture versus Tack Mesh Fixation. Surgical Endoscopy, 25, 749-755. http://dx.doi.org/10.1007/s00464-010-1246-0

[37] Kaoutzanis, C., Leichtle, S.W., Mouawad, N.J., Welch, K.B., Lampman, R.M. and Cleary, R.K. (2013) Postoperative Surgical Site Infections after Ventral/Incisional Hernia Repair: A Comparison of Open and Laparoscopic Outcomes. Surgical Endoscopy, 27, 2221-2230. http://dx.doi.org/10.1007/s00464-012-2743-0

[38] Cihan, A., Ozdemir, H., Ucan, B.H., Acun, Z., Comert, M., Tascilar, O., et al. (2006) Fade or Fate. Seroma in Laparoscopic Inguinal Hernia Repair. Surgical Endoscopy and Other Interventional Techniques, 20, 325-328. http://dx.doi.org/10.1007/s00464-005-0052-6

[39] Bedi, A.P., Bhatti, T., Amin, A. and Zuberi, J. (2007) Laparoscopic Incisional and Ventral Hernia Repair. Journal of Minimal Access Surgery, 3, 83-90. http://dx.doi.org/10.4103/0972-9941.37190

[40] Morales-Conde, S. (2012) A New Classification for Seroma after Laparoscopic Ventral Hernia Repair. Hernia, 16, 261-267. http://dx.doi.org/10.1007/s10029-012-0911-8 
Scientific Research Publishing (SCIRP) is one of the largest Open Access journal publishers. It is currently publishing more than 200 open access, online, peer-reviewed journals covering a wide range of academic disciplines. SCIRP serves the worldwide academic communities and contributes to the progress and application of science with its publication.

Other selected journals from SCIRP are listed as below. Submit your manuscript to us via either submit@scirp.org or Online Submission Portal.
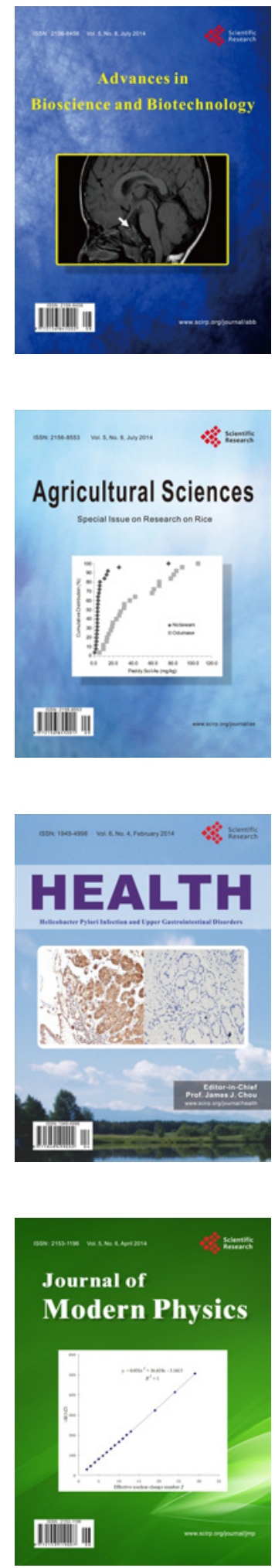
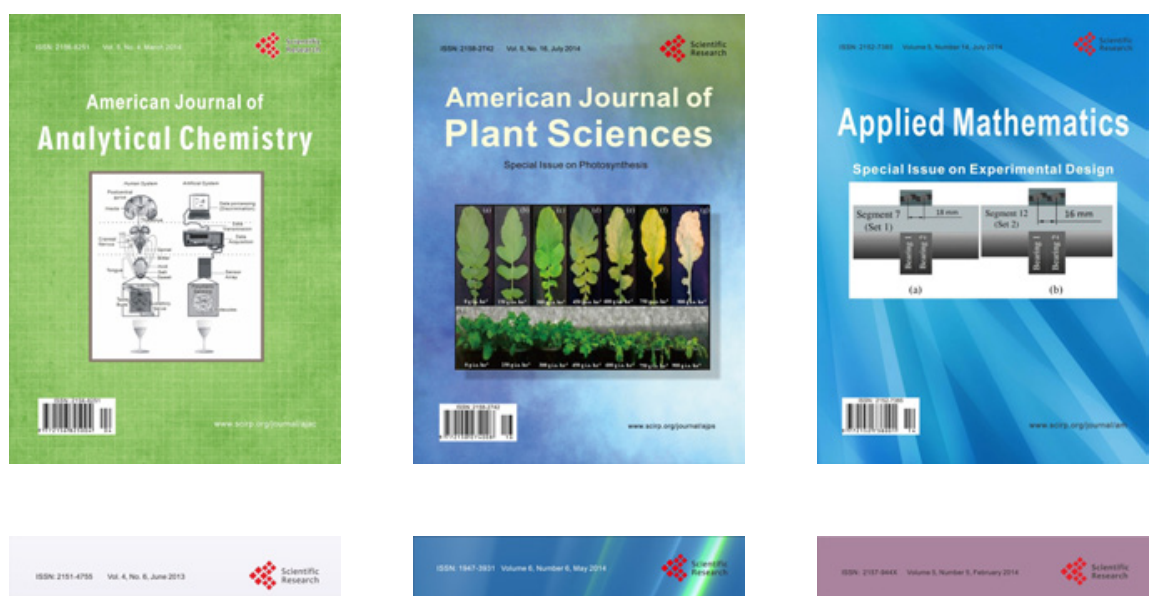

Creative Education
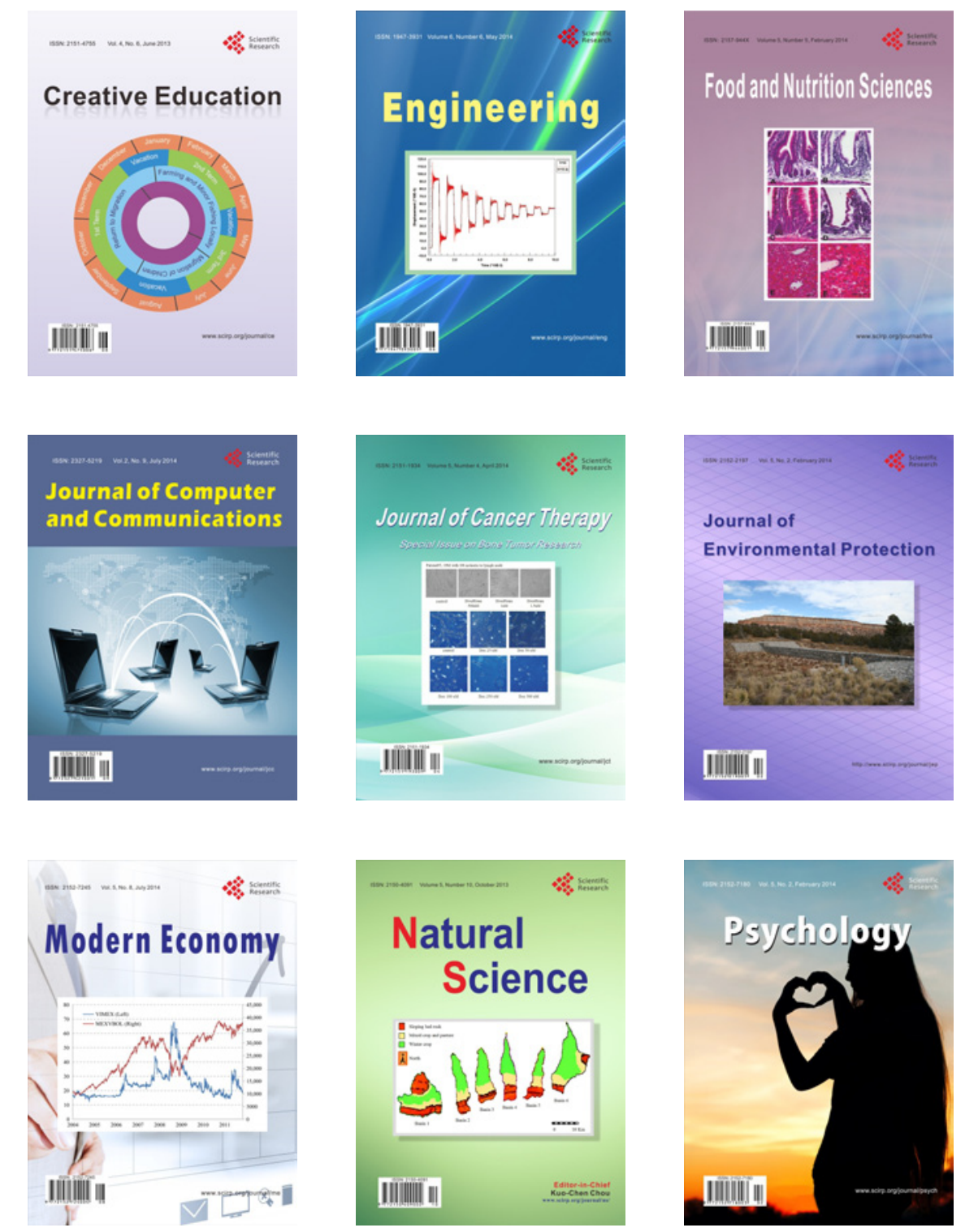